\title{
Preliminary clinical and pharmacologic investigation of photodynamic therapy with the silicon phthalocyanine photosensitizer Pc 4 for primary or metastatic cutaneous cancers
}

\author{
Timothy James Kinsella, ${ }^{1,2+}$, Elma D. Baron ${ }^{2,3,4,5}$, Valdir C. Colussi' ${ }^{1}$, Kevin D. Cooper ${ }^{2,3,4,5}$, Charles L. Hoppel ${ }^{2,6}$, \\ Stephen T. Ingalls ${ }^{6}$, Malcolm E. Kenney ${ }^{7}$, Xiaolin Li ${ }^{6}$, Nancy L. Oleinick ${ }^{2,8 *}$, Seth R. Stevens ${ }^{2,3,4,5 t}$ and \\ Scot C. Remick ${ }^{9,10 t}$
}

\author{
1 Department of Radiation Oncology, University Hospitals Case Medical Center, Cleveland, OH, USA \\ 2 Case Comprehensive Cancer Center, Case Western Reserve University, Cleveland, OH, USA \\ ${ }^{3}$ Department of Dermatology, Case Western Reserve University, Cleveland, OH, USA \\ 4 Department of Dermatology, University Hospitals Case Medical Center, Cleveland, OH, USA \\ ${ }_{5}^{5}$ Dermatology Service, Louis Stokes Cleveland Department of Veterans Affairs Medical Center, Cleveland, OH, USA \\ ${ }^{6}$ Department of Pharmacology, Case Western Reserve University, Cleveland, OH, USA \\ 7 Department of Chemistry, Case Western Reserve University, Cleveland, OH, USA \\ ${ }^{8}$ Department of Radiation Oncology, Case Western Reserve University, Cleveland, OH, USA \\ ${ }_{9}^{9}$ Department of Medicine, University Hospitals Case Medical Center, Cleveland, OH, USA \\ ${ }^{10}$ Department of Medicine, Case Western Reserve University, Cleveland, OH, USA
}

\section{Edited by:}

Silvia Formenti, New York Langone

Cancer Institute, USA

\section{Reviewed by:}

Sylvia Adams, New York University, USA

Shisuo Du, Fudan University, China

*Correspondence:

Nancy L. Oleinick, Department of Radiation Oncology, School of

Medicine (BRB-324), Case Western

Reserve University, 10900 Euclid

Avenue, Cleveland, $\mathrm{OH}$ 44106-4942,

USA.

e-mail:nlo@case.edu

\section{${ }^{+}$Current address:}

Timothy James Kinsella, Department of Radiation Oncology, Warren Alpert Medical School, Brown University, Providence, RI 02903, USA;

Seth R. Stevens, Department of

Dermatology, Woodland Hills Medical Center, Permanente Medical Group, Woodland Hills, CA 91367, USA Scot C. Remick, Mary Babb Randolph Cancer Center, West Virginia University School of Medicine, Morgantown, WV 26506, USA.
Photodynamic therapy (PDT) for cutaneous malignancies has been found to be an effective treatment with a range of photosensitizers. The phthalocyanine Pc 4 was developed initially for PDT of primary or metastatic cancers in the skin. A Phase I trial was initiated to evaluate the safety and pharmacokinetic profiles of systemically administered $\mathrm{Pc}_{\mathrm{c}} 4$ followed by red light $(\mathrm{Pc}$ 4-PDT) in cutaneous malignancies. A dose-escalation study of Pc 4 (starting dose $0.135 \mathrm{mg} /$ $\left.\mathrm{m}^{2}\right)$ at a fixed light fluence $\left(135 \mathrm{~J} / \mathrm{cm}^{2}\right.$ of $675-\mathrm{nm}$ light) was initiated in patients with primary or metastatic cutaneous malignancies with the aim of establishing the maximum tolerated dose (MTD). Blood samples were taken at intervals over the first $60 \mathrm{~h}$ post-PDT for pharmacokinetic analysis, and patients were evaluated for toxicity and tumor response. A total of three patients (two females with breast cancer and one male with cutaneous T-cell lymphoma) were enrolled and treated over the dose range of $0.135 \mathrm{mg} / \mathrm{m}^{2}$ (first dose level) to $0.54 \mathrm{mg} / \mathrm{m}^{2}$ (third dose level). Grade 3 erythema within the photoirradiated area was induced in patient 2, and transient tumor regression in patient 3 , in spite of the low photosensitizer doses. Pharmacokinetic observations fit a three-compartment exponential elimination model with an initial rapid distribution phase $(\sim 0.2 \mathrm{~h})$ and relatively long terminal elimination phase $(\sim 28 \mathrm{~h})$, Because of restrictive exclusion criteria and resultant poor accrual, the trial was closed before MTD could be reached. While the limited accrual to this initial Phase I study did not establish the MTD nor establish a complete pharmacokinetic and safety profile of intravenous Pc 4-PDT, these preliminary data support further Phase I testing of this new photosensitizer.

Keywords: cutaneous cancers, phthalocyanine, Pc 4, photodynamic therapy

\section{INTRODUCTION}

Photodynamic therapy (PDT) is now approved by the US Food and Drug Administration (FDA) for a range of cancers and noncancerous indications: specifically, early and advanced lung cancer, advanced esophageal cancer, and Barrett's esophagus with porfimer sodium (Photofrin ${ }^{\circ}$ ) as the photosensitizer; age-related macular degeneration with benzoporphyrin derivative (Verteporfin $\left.{ }^{\circledR}\right)$; and actinic keratosis with 5 -aminolevulinic acid (ALA; Levulan ${ }^{\circ}$ ) or methyl aminolevulinate (Metvixia $\left.{ }^{\circledR}\right)$. Approvals for other indications and additional photosensitizers have been received in many other countries worldwide, and further clinical studies are in process with these and other photosensitizers (Dolmans et al., 2003; Brown et al., 2004; Huang et al., 2008).

For metastatic breast cancer to the chest wall, PDT has been reported to produce partial or complete responses in a significant proportion of patients using several different photosensitizers, including rostaporfin (Purlytin ${ }^{\circledR}$; Mang et al., 1998), Photofrin ${ }^{\varpi}$ (Allison et al., 2001; Cuenca et al., 2004), motexafin lutetium (Antrin ; Renschler et al., 1998; Dimofte et al., 2002), and temoporfin (Foscan ${ }^{\circ}$; Wyss et al., 2001). Trials through 2004 have been reviewed (Allison et al., 
2004). For cancer, precancerous lesions, and benign conditions of the skin, the most widely used procedure involves topical delivery of ALA formulated as Levulan ${ }^{\varpi}$ or Metvixia ${ }^{\circledast}$ and photoirradiation after a delay to allow metabolic conversion of ALA to the photosensitizer, protoporphyrin IX (Morton et al., 2008). Nonetheless, PDT with preformed photosensitizers, such as Photofrin ${ }^{\circledast}$, has been found to be efficacious against skin cancers (e.g., Oseroff et al., 2006). In spite of the demonstrated success of PDT, there are no US FDA approvals for the use of PDT in skin cancers.

Pc 4 is a silicon phthalocyanine first synthesized in the laboratory of M.E. Kenney, Chemistry Department, Case Western Reserve University (CWRU; Figure 1; Oleinick et al., 1993). After demonstration of the efficacy of Pc 4 as a photosensitizer for PDT against a variety of cancer cell lines in vitro and model tumors in vivo (e.g., Zaidi et al., 1993; Agarwal et al., 1996; Anderson et al., 1997, 1998), investigators at CWRU petitioned the Drug Decision Network (DDN), a division of the Cancer Therapy Evaluation Program (CTEP) of the National Cancer Institute (NCI), for help in conducting the additional studies needed for application to the FDA for an investigational new drug (IND) designation with permission to conduct the first clinical trial of PDT with systemic delivery of Pc 4 for cutaneous malignancies. From 1995 to 1998, CTEP oversaw the good manufacturing practices (GMP) synthesis of Pc 4, reformulation into an acceptable vehicle, pharmacokinetic studies in mice (Egorin et al., 1999), further efficacy studies (Colussi et al., 1999), and toxicity studies conducted under good laboratory practices (GLP). The resultant data were submitted to the FDA in the form of a drug master file (DMF) that was cross-referenced by CWRU investigators in their application for an IND $(\# 61,155)$.

A Phase I trial of PDT with intravenously administered Pc 4 for cutaneous malignancies was initially activated and further amended in an attempt to improve patient accrual. In spite of all efforts, accrual was poor and the trial was closed. However, three patients were treated with interesting results. This paper reports on these limited clinical and pharmacologic results as well as commentary on further clinical development of Pc 4-PDT.

\section{MATERIALS AND METHODS TRIAL DESIGN}

The Phase I protocol was designed first to escalate the dose of Pc 4 at a constant light fluence to determine the maximum tolerated dose (MTD), after which a Pc 4 dose one level lower would be
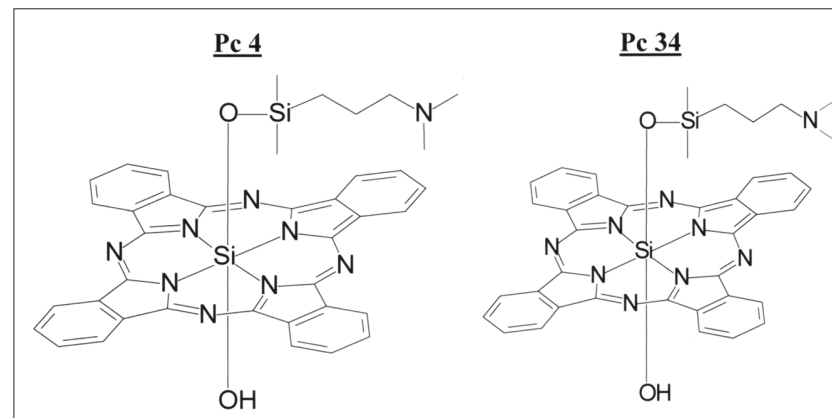

FIGURE 1 | Structures of Pc 4 and Pc 34. Pc 4 is the photosensitizer studied in the clinical trial. Pc 34 is a closely related molecule used as an internal standard for HPLC analysis. administered with increasing fluence. A dose-escalation study of Pc 4 with a fixed light dose $\left(135 \mathrm{~J} / \mathrm{cm}^{2}\right.$ of $675 \pm 5 \mathrm{~nm}$ light from a laser) was designed. Since the starting dose of Pc 4 (0.135 mg/ $\mathrm{m}^{2} ; 0.0039 \mathrm{mg} / \mathrm{kg}$ ), as set in negotiations with the FDA, was lower than those of any of the currently used photosensitizers, a 100\% dose-escalation scheme in single-patient cohorts was approved with the endpoint being skin erythema in the treated (illuminated) area, after which three-patient cohorts were required.

The pharmacokinetic sampling strategy was based on elimination half-life and clearance values for Pc 4 determined in mice (Egorin et al., 1999). A distribution half-life of $10 \mathrm{~min}$ and an elimination half-life of $36 \mathrm{~h}$ were modeled. During the 2-h Pc 4 infusion, blood samples were taken at $0,30,60$, and $120 \mathrm{~min}$ and then post-infusion samples were taken at $0.5,1,2,4,8,12,18,24$, 36,48 , and $60 \mathrm{~h}$.

\section{PATIENT COHORT AND EXCLUSION CRITERIA}

The protocol was approved by the Institutional Review Board of University Hospitals of Cleveland, and written informed consent was obtained from each volunteer. Patients with pathologically confirmed cutaneous or superficial nodular metastatic/locally recurrent breast adenocarcinoma or head-and-neck squamous cell carcinoma with a minimum of 1 well-defined tumor lesion of $1.5-3.0 \mathrm{~cm}^{2}$ were eligible. Up to two separate lesions could be treated with the maximum of $16 \mathrm{~cm}^{2}$ area per treatment site to allow a $3-\mathrm{cm} \times 3-\mathrm{cm}$ tumor mass with a $1-\mathrm{cm}$ margin to be illuminated. These solid tumor patients were judged to have no potential for cure by conventional treatment modalities including surgery, radiation, and chemotherapy. Prior treatment with radiation and chemotherapy was allowed if patients were without these conventional treatments for at least 4 weeks prior to study entry. Additionally, patients with biopsy-confirmed, conventional treatment-refractory cutaneous T-cell lymphoma (CTCL) or Kaposi's sarcoma with similar skin lesion criteria were also eligible. Exclusion criteria included: hematologic dysfunction (absolute neutrophil count, $<1500 / \mu \mathrm{L}$; hemoglobin, $<9$ g/dL; platelets, $<100,000 / \mu \mathrm{L})$; coagulation dysfunction (APTT and PT $>1.2 \times$ normal); hepatic dysfunction $\left(\mathrm{B}_{12}>1.5 \mathrm{mg} / \mathrm{dL}\right.$; transaminases $>2 \times$ normal $)$; renal dysfunction (creatinine $>2.0 \mathrm{mg} / \mathrm{dL}$ or creatinine clearance $<50 \mathrm{~mL} / \mathrm{min}$ ); and lipid disorder (cholesterol and triglyceride serum levels $>3 \times$ normal) within 7 days of protocol entry. Other exclusion criteria included: cardiovascular dysfunction (MI within 6 months; active congestive heart failure); known photosensitivity diseases including porphyria and xeroderma pigmentosum; and the concomitant use of potentially photosensitizing medications including certain antibiotics (tetracyclines, sulfas), diuretics (hydrochlorothiazide, furosemide), and phenothiazines.

\section{FORMULATION AND INFUSION OF PC 4}

Pc 4 drug was received in the University Hospitals Investigational Pharmacy as dual vials, one with $1 \mathrm{mg}$ Pc 4 and $5 \mathrm{mg}$ Povidone, the second with $1 \mathrm{~mL}$ of Cremophor EL:ethanol::1:1 (NCI Diluent 12). Under contract with the NCI, the vials were prepared by BenVenue Laboratories, Oakwood, OH, USA. The hospital pharmacist dissolved the drug powder in NCI Diluent 12, then diluted it with 9 volumes of normal saline. Patients were given the formulated Pc 4 intravenously through an infusion pump over a 2-h period. 


\section{PHOTODYNAMIC THERAPY}

Selected tumor sites were photoirradiated $24 \mathrm{~h}$ after administration of Pc 4. This time interval between drug delivery and light delivery was selected to allow differential tumor to normal skin drug clearance, based on preclinical animal studies (Egorin et al., 1999). Each site received $135 \mathrm{~J} / \mathrm{cm}^{2}$ at an irradiance of $100 \mathrm{~mW} / \mathrm{cm}^{2}$ with a 675-nm diode laser (LaserCare PDT 674-8, AOC Medical Systems, South Plainfield, NJ, USA). The surface of the skin tumor was illuminated through a fiberoptic cable terminating in a microlens (Pioneer Optics Co., Windsor Locks, CT, USA). The laser unit was self-calibrated using the integrating sphere power meter of the diode laser. The microlens output was measured prior to and after each PDT session using a second remote power meter (LaserMateA/D-10 Head Calibration, Coherent, Inc., Santa Clara, CA, USA). The Laser Mate, in turn, was calibrated annually using a National Institute of Science and Technology (NIST)-traceable calibrator.

\section{RESPONSE CRITERIA}

Tumor responses were determined using bidimensional measurements to estimate the surface area of each lesion and measurement of the maximum lesion height. Photographs of the skin lesions also were taken immediately prior to PDT and every 4 weeks thereafter. Using a modification of standard NCI response criteria, a complete response was defined by a $100 \%$ decrease in lesion area and height at $\geq 4$ weeks following PDT; a partial response as 50\% decrease in area and/or height; stable disease as a $<25 \%$ increase or $<50 \%$ decrease in lesion area and $<100 \%$ flattening of a raised lesion on height assessment; and progressive disease as $>25 \%$ increase in lesion area and/or height.

Toxicity assessment included use of NCI Expanded Common Toxicity Criteria (version 2.0) for systemic toxicity as well as a modified five-grade peri-lesional skin (immediately outside the light field) toxicity assessment (Carraro and Pathak, 1988). Additionally, minimal erythema dose (MED) was assessed on distant skin in the first patient (study patient 3 ) after the one (study patient 2) who developed erythema following laser irradiation at the tumor site. A five-grade MED scoring system was used based on testing with a solar simulator using full spectrum UVA and UVB $(280-400 \mathrm{~nm})$ at a dose range of approximately $5-60 \mathrm{~mJ} / \mathrm{cm}^{2}$.

\section{PHARMACOKINETICS OF PC 4}

Plasma samples were obtained from patient volunteers by venipuncture contralateral to the infusion site before infusion initiation, at 0.5 and $1.0 \mathrm{~h}$ after infusion initiation, just before infusion termination, and subsequently at $0.5-60 \mathrm{~h}$ after infusion termination. Pc 4 was determined by high performance liquid chromatography/tandem mass spectrometry according to a method developed by the Case Comprehensive Cancer Center Cancer Pharmacology Core Laboratory. Pc 4 and the closely analogous Pc 34 (Figure 1) internal standard were extracted from $200-\mu$ aliquots of plasma with good efficiency. The organic extracts were evaporated to dryness, reconstituted in chromatographic mobile phase, and injected into the liquid chromatograph. The chromatographic separation was accomplished on a reverse-phase column with an isocratic mobile phase consisting of methanol and ammonium formate buffer. Pc 4 and Pc 34 were detected by monitoring collisioninduced transitions of $718-557 \mathrm{~m} / \mathrm{z}$ and $746-557 \mathrm{~m} / \mathrm{z}$, respectively. Plasma samples and concurrent quality control specimens were prepared and analyzed in duplicate, and Pc 4 concentrations were calculated in relation to calibration curves established over the range of $0.078-100 \mathrm{nM}$ Pc 4 in plasma during each episode of sample analysis. The lower limit of quantitation corresponds with about $2 \times 10^{-15} \mathrm{~mol}$ of Pc 4 injected into the chromatographic column.

\section{RESULTS}

After activation of the trial, over the next 13 months, a large number of patients were identified by referring physicians and, of those, 35 patients were screened to determine if they qualified for the trial. In spite of the intensive screening, no patients were found to fit all of the criteria for the trial. Recognizing that the inclusion and exclusion criteria were written quite narrowly to satisfy requirements negotiated with the FDA, the investigators petitioned the FDA for expansion of the inclusion criteria to increase lesion size for treatment from 3 to $5 \mathrm{~cm}^{2}$, to allow concurrent hormonal therapy for breast cancer patients, and to include other tumors, such as colon cancer, that also metastasize to skin. The amended protocol was approved.

A total of three patients (two females with breast cancer and one male with CTCL) were enrolled and treated over the dose range of $0.135 \mathrm{mg} / \mathrm{m}^{2}$ (first dose level) to $0.54 \mathrm{mg} / \mathrm{m}^{2}$ (third dose level; Table 1). No dose-limiting systemic toxicities were encountered. The first two patients showed progressive disease at week 4 following the first PDT treatment. However, quite unexpectedly early in the dose-escalation experience, patient 2 developed grade 3 erythema at dose level $2\left(0.27 \mathrm{mg} / \mathrm{m}^{2}\right)$ for which expansion of patients treated at this dose level was required. Patient 3 went on to be treated at dose level 2 and tolerated therapy for 2 cycles. Since

Table 1 | Clinical tumor response and normal skin phototoxicity data.

\begin{tabular}{|c|c|c|c|c|c|}
\hline Pt no. & Tumor type & $\begin{array}{l}\text { Pc } 4 \text { dose } \\
\left(\mathrm{mg} / \mathrm{m}^{2}\right)\end{array}$ & $\begin{array}{l}\text { No. PDT } \\
\text { cycles }\end{array}$ & Tumor response & Normal skin phototoxicity \\
\hline 1 & Recurrent breast cancer & 0.135 & 1 & $\begin{array}{l}\text { No erythema to adjacent skin following PDT; } \\
\text { tumor progression at week } 4\end{array}$ & $\begin{array}{l}\text { Not tested for MED; none observed } \\
\text { clinically }\end{array}$ \\
\hline 2 & Recurrent breast cancer & 0.27 & 1 & $\begin{array}{l}\text { Grade } 3 \text { erythema to adjacent skin following } \\
\text { PDT; tumor progression at week } 4\end{array}$ & $\begin{array}{l}\text { Not tested for MED; none observed } \\
\text { clinically }\end{array}$ \\
\hline \multirow[t]{2}{*}{3} & Refractory CTCL & 0.27 & 2 & $\begin{array}{l}\text { Stable disease }(<50 \%) \text { response at weeks } 4 \\
\text { and } 8\end{array}$ & $\begin{array}{l}\text { No change in MED pre- vs. post-Pc } \\
4 ; \text { none observed clinically }\end{array}$ \\
\hline & & 0.54 & 2 & $\begin{array}{l}\text { Stable disease }(<50 \%) \text { response at week } 12 \\
\text { and } 16 \text {; tumor progression at week } 20\end{array}$ & None observed clinically \\
\hline
\end{tabular}


there was evidence of tumor regression (however, not sufficient to meet criteria for partial response), he was allowed to undergo an intra-patient dose-escalation to the third dose level. He was treated for two additional cycles at $0.54 \mathrm{mg} / \mathrm{m}^{2}$. By the time regulatory approval was secured to proceed with a second intra-patient dose-escalation, the patient developed progressive disease. In all, patient 3 received 4 cycles of therapy. MED testing on distant skin was conducted on patient 3 during the first treatment cycle and revealed no increase in cutaneous photosensitivity 1 day after infusion of Pc 4 (pre-infusion MED: $41.83 \mathrm{~mJ} / \mathrm{cm}^{2} ; 1$ day post-infusion MED: $\left.49.49 \mathrm{~mJ} / \mathrm{cm}^{2}\right)$.

As per protocol design, pharmacokinetics of Pc 4 were determined during drug infusion and for up to $60 \mathrm{~h}$ following the 2 -h infusion. Pc 4 concentrations were measurable in plasma specimens from patient $1\left(0.135 \mathrm{mg} / \mathrm{m}^{2}\right.$ Pc 4 over $\left.2 \mathrm{~h}\right)$ obtained throughout the full duration of the sampling period (Figure 2). The plasma concentration of Pc 4 determined $60 \mathrm{~h}$ after infusion termination was about two times the lower limit of quantitation of the assay method. The plasma concentration vs. time data subsets from the end of the infusion period through $60 \mathrm{~h}$ post-infusion were fit well by a three-exponential-term pharmacokinetic model. These terms characterize a rapid distribution phase with a half-life of $0.2 \mathrm{~h}$, an intergrade elimination rate

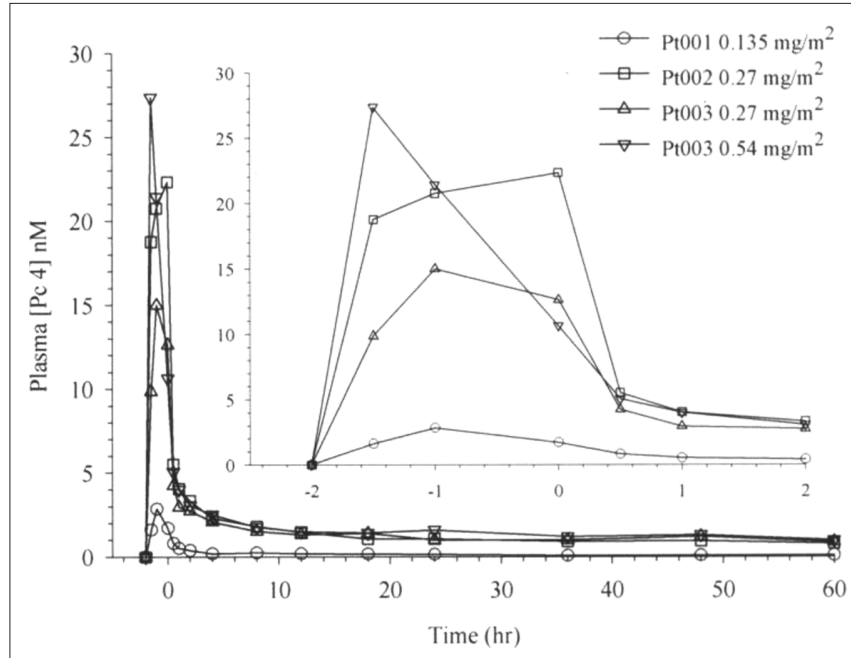

FIGURE 2 | Plasma Pc 4 concentration vs. time plots for four data sets obtained from three study volunteers in four treatment experiments. The inset presents data for the early period on an expanded time scale. phase with an apparent half-life of $0.8 \mathrm{~h}$, and a comparatively slow terminal elimination phase with a half-life of $28.6 \mathrm{~h}$ in this data set.

Patient 2 received a dose of $0.27 \mathrm{mg} / \mathrm{m}^{2}$ of Pc 4 in a 2-h infusion (Figure 2). The maximum plasma concentration $\left(C_{\max }\right)$ of $22.3 \mathrm{nM}$ measured in this experiment exceeded the $C_{\max }$ of $2.9 \mathrm{nM}$ measured in plasma from Patient 1 by more than sevenfold. Trapezoidal AUC calculated for the end of infusion and post-infusion data subset exceeded that observed in patient 1 by a similar multiple, and other calculated pharmacokinetic parameters also differed from those observed in Patient 1 (Figure 2; Tables 2 and 3). We decided consequently to study another patient at a dose of $0.27 \mathrm{mg} / \mathrm{m}^{2}$ of Pc 4. Results obtained from Patient 3 generally were similar to those obtained from Patient 2. Subsequently, Patient 3 was treated again with a dose of $0.54 \mathrm{mg} / \mathrm{m}^{2}$ of Pc 4 . Data sets from all four experiments appear in Figure 2.

Maximum measured Pc 4 concentrations did not coincide with the end of infusion sample time point in three of four experimental data sets (Table 3; Figure 2). The experimental protocol required infusion of small volumes of Pc 4 infusate solution at flow rates near the lower limit of capability of the infusion pumps used for drug delivery. We think that this variation in time of maximum measured Pc 4 concentration probably results from drug delivery inconsistency during the infusion phase of the experiment.

\section{DISCUSSION}

While our Phase I study clearly did not establish the MTD nor a complete pharmacokinetic and safety profile of Pc 4, these preliminary results support further Phase I testing of Pc 4-PDT. This is substantiated by the induction of grade 3 erythema within the treatment area in the second patient and transient ( 12 weeks) tumor regression, though not of sufficient duration to meet objective partial response $(>50 \%)$ criteria, in the third patient treated in

Table 2 | Maximum measured concentrations of $\operatorname{Pc} 4\left(C_{\max }\right)$ and concentrations at end of infusion (Ceoi).

\begin{tabular}{llccc}
\hline & Dose $\left(\mathbf{m g} / \mathbf{m}^{2}\right)$ & Time $\boldsymbol{C}_{\max }(\mathbf{h})$ & $\boldsymbol{C}_{\max }(\mathbf{n M})$ & Ceoi (nM) \\
\hline Pt001 & 0.135 & -1 & 2.9 & 1.7 \\
Pt002 & 0.27 & 0 & 22.3 & 22.3 \\
Pt003 & 0.27 & -1 & 15.0 & 12.6 \\
Pt003 & 0.54 & -1.5 & 27.4 & 10.6 \\
\hline
\end{tabular}

The end of infusion time is defined as hour zero.

Table 3 | Pharmacokinetic parameters of Pc 4 in the elimination phase data subsets.

\begin{tabular}{|c|c|c|c|c|c|c|}
\hline & Dose $\left(\mathrm{mg} / \mathrm{m}^{2}\right)$ & B1 $t_{1 / 2}(h)$ & B2 $t_{1 / 2}(h)$ & B3 $t_{1 / 2}(h)$ & AUC (last $\left.t, n M^{*} h\right)$ & AUC (inf; nM*h) \\
\hline Pt001 & 0.135 & 0.20 & 0.79 & 28.6 & 9.1 & 11.6 \\
\hline Pt002 & 0.27 & 0.13 & 2.43 & 64.6 & 80.8 & 148.9 \\
\hline Pt003 & 0.27 & 0.16 & 3.09 & 145.4 & 79.5 & 279.0 \\
\hline Pt003 & 0.54 & 0.18 & 2.04 & 90.9 & 91.5 & 231.4 \\
\hline
\end{tabular}

A three-exponential term pharmacokinetics model described the data well. The B1, B2, and B3 half lives are tabulated for discernible rapid, intermediate rate, and

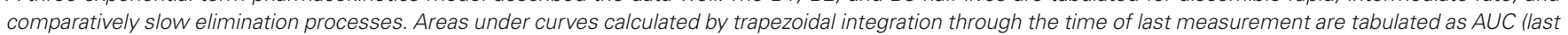
t). Areas under curves calculated from model time constant parameters and projected to infinite time are tabulated as AUC (inf). 
this study. Further, these positive responses were obtained with a relatively low dose of photosensitizer $\left(0.27 \mathrm{mg} / \mathrm{m}^{2}\right)$. The highest dose tested was only $0.54 \mathrm{mg} / \mathrm{m}^{2}$, which is equivalent to $0.0156 \mathrm{mg} /$ $\mathrm{kg}$. This dose level is nearly an order of magnitude lower than the recommended doses of Foscan ${ }^{\circledast}(0.1-0.15 \mathrm{mg} / \mathrm{kg}$; Triesscheijn et al., 2006), which are the lowest of all clinically approved photosensitizers. The transient tumor regression observed at a very low dose for Pc 4, along with the absence of significant toxicity, is consistent with the potential of Pc 4 as a photosensitizer in PDT protocols for cutaneous malignancies.

Our pharmacokinetic observations fit a three-compartment exponential elimination model with an initial rapid distribution phase $(\sim 0.2 \mathrm{~h})$ and relatively long terminal elimination phase $(\sim 28 \mathrm{~h})$, which were consistent with preclinical observations in mice (Egorin et al., 1999).

Due to the restrictive eligibility criteria, and the resultant poor accrual that led to early closing of the trial, it was decided to explore the possibility of delivering Pc 4 topically to skin lesions. A topical formulation was developed in 30\% propylene glycol/70\% ethanol. Experiments to evaluate the ability of that formulation to deliver Pc 4 across the skin barrier were first conducted on human skin keratomes in vitro and resulted in a demonstration of the ability of Pc 4 to cross the stratum corneum and penetrate through the epidermis to the dermal-epidermal junction (Lam et al., 2011). Additional in vitro studies revealed a high susceptibility of T-cells to Pc 4-PDT: Jurkat T-cells were found to be much more sensitive to Pc 4-PDT than were A 431 human keratinocyte-derived cells, and the dominant mechanism of cell death in the T-cells was apoptosis (Ke et al., 2008). Apoptosis is a prominent mode of cell death for many cancer cells in response to Pc 4-PDT in vitro as well as in vivo (Oleinick et al., 2002; Miller et al., 2007). Evidence for apoptosis was also obtained in peripheral blood mononuclear cells from patients with Sezary Syndrome, a form of CTCL; at all PDT doses, there was significantly greater induction of apoptosis among CD4+ CD7malignant T-cells compared to either non-malignant or monocytic cells (Lam et al., 2010). Finally, activated T-cells were found to be

\section{REFERENCES}

Agarwal, R., Korman, N. J., Mohan, R. R., Feyes, D. K., Jawed, S., Zaim, M. T., and Mukhtar, H. (1996). Apoptosis is an early event during phthalocyanine photodynamic therapy-induced ablation of chemically induced squamous papillomas in mouse skin. Photochem. Photobiol. 63, 547-552.

Allison, R., Sibata, C., Mang, T. S., Bagnato, V. S., Downie, G. H., Hu, X. H., and Cuenca, R. (2004). Photodynamic therapy for chest wall recurrence from breast cancer. Photodiagnosis Photodyn. Ther. 1, 157-171.

Allison, R. R., Mang, T. S., Hewson, G., Snider, W., and Dougherty, T. J. (2001). Photodynamic therapy for chest wall progression from breast carcinoma is an underutilized treatment modality. Cancer 91, 1-8.

Anderson, C., Hrabovsky, S., McKinley, Y., Tubesing, K., Tang, H.-P., Dunbar, pharmacologic inhibitors on cutane-

more sensitive to Pc 4-PDT in vitro than normal quiescent T-cells (Ohtola et al., 2010). Thus, these studies suggested that Pc 4-PDT has the potential to induce selective apoptosis of pathologic T-cells critical for T-cell-mediated diseases such as CTCL.

Based on the response of the CTCL lesions of patient 3 to low doses of Pc 4-PDT as described above and the evidence of high sensitivity of T-cells to this treatment, a new protocol was developed to apply Pc 4 topically to cutaneous malignancies and then photoirradiate $1 \mathrm{~h}$ later. This protocol was approved by the FDA under the existing IND number. A total of 43 patients were accrued to that trial, and the results have recently been published (Baron et al., 2010). Briefly, it was shown that Pc 4-PDT with topically administered photosensitizer was well tolerated with no significant local toxicity or increased photosensitivity at distant sites. Furthermore, Pc 4-PDT was shown to have promising biologic effects, particularly in mycosis fungoides-type CTCL, in which 14 of 35 subjects demonstrated a clinical response. A few patients in this trial provided biopsies of treated and untreated lesions; study of them produced evidence of increased apoptosis in tissue from responding lesions.

Our general conclusion is that, in spite of the early termination of the trial of systemically administered Pc 4 for PDT of cutaneous malignancies, Pc 4 has the potential to be an efficacious photosensitizer in PDT protocols. Based on these limited clinical and pharmacokinetic data of intravenous Pc 4-PDT, further Phase I testing is being considered for other appropriate tumors including superficial, minimally invasive cancers of the bladder, esophagus, and head-and-neck, where Pc 4-PDT may have a better therapeutic index compared to surgery, radiation therapy, chemotherapy, or other photosensitizers.

\section{ACKNOWLEDGMENTS}

This research was supported by the Case Comprehensive Cancer Center Support Grant P30 CA43703, Program Project Grant P01 CA48735, Phase I Contract U01 CA62502, and Skin Diseases Research Center Grant P50 AR055508 from the National Institutes of Health. Supported in part, by the DBJ Foundation.

a phase 1 clinical trial. Lasers Surg. Med. 42, 728-735.

R., Mukhtar, H., and Elmets, C. A. (1997). Phthalocyanine photodynamic therapy: disparate effects of ous photosensitivity and on tumor regression. Photochem. Photobiol. 65, 895-901.

Anderson, C. Y., Freye, K., Tubesing, K.A., Li, Y.-S., Kenney, M. E., Mukhtar, H., and Elmets, C. A. (1998). A comparative analysis of silicon phthalocyanine photosensitizers for in vivo photodynamic therapy of RIF-1 tumors in C3H mice. Photochem. Photobiol. 67, 332-336.

Baron, E. D., Malbasa, C. L., SantoDomingo, D., Fu, P., Miller, J. D., Hanneman, K. K., Hsia, A. H., Oleinick, N. L., Colussi, V. C., and Cooper, K. D. (2010). Silicon phthalocyanine (Pc 4) photodynamic therapy is a safe modality for cutaneous neoplasms: results of I. (2004). The present and future role of photodynamic therapy in cancer treatment. Lancet Oncol. 5, 497-508.

Carraro, C., and Pathak, M. A. (1988) Studies on the nature of in vitro and in vivo photosensitization reactions by psoralens and porphyrins. J. Invest. Dermatol. 90, 267-275.

Colussi, V. C., Feyes, D. K., Mulvihill, J. W., Li, Y.-S., Kenney, M. E., Elmets, C. A., Oleinick, N. L., and Mukhtar, H. (1999). Phthalocyanine (Pc 4) photodynamic therapy of human OVCAR-3 tumor xenografts. Photochem. Photobiol. 69, 236-241.

Cuenca, R. E., Allison, R. R., Sibata, C., and Downie, G. H. (2004). Breast cancer with chest wall progression: treatment with photodynamic therapy. Ann Surg. Oncol. 11, 322-327.
Dimofte, A., Zhu, T. C., Hahn, S. M., and Lustig, R. A. (2002). In vivo light dosimetry for motexafin lutetiummediated PDT of recurrent breast cancer. Lasers Surg. Med. 31, 305-312.
Dolmans, D. E. J. G. J., Fukumura, D., and Jain, R. K. (2003). Photodynamic therapy for cancer. Nat. Rev. Cancer 3, 380-387.

Egorin, M. J., Zuhowski, E. G., Sentz, D. L., Dobson, J. M., Callery, P. S., and Eiseman, J.L. (1999). Plasma pharmacokinetics and tissue distribution in CD2F1 mice of Pc 4 (NSC 676418), a silicon phthalocyanine photodynamic sensitizing agent. Cancer Chemother. Pharmacol. 44, 283-294.

Huang, Z., Xu, H., Meyers, A. D., Musani, A. I., Wang, L., Tagg, R., Barqawi,A. B., and Chen, Y. K. (2008). Photodynamic therapy for treatment of solid tumors - potential and technical challenges. Technol. Cancer Res. Treat. 7,309-320. 
Ke, M.S., Xue, L.Y., Feyes, D. K., Azizuddin, K., Baron, E. D., McCormick, T. S., Mukhtar, H., Panneerselvam, A., Schluchter, M. D., Cooper, K. D., Oleinick, N. L., and Stevens, S. R. (2008).Apoptosis mechanisms related to the increased sensitivity of Jurkat T-cells versus A-431 epidermoid cells to photodynamic therapy with the phthalocyanine Pc 4. Photochem. Photobiol. 84, 407-414.

Lam, M., Lee, Y., Deng, M., Hsia, A. H., Morrissey, K. A., Yan, C., Azzizudin, K., Oleinick, N. L., McCormick, T. S., Cooper, K. D., and Baron, E. D. (2010). Photodynamic therapy with the silicon phthalocyanine Pc 4 induces apoptosis in mycosis fungoides and Sezary syndrome. Adv. Hematol. 2010, 896161.

Lam, M., Liu, Y., Hsia, A. H., Oleinick, N. L., Kenney, M. E., McCormick, T. D., Cooper, K. D., and Baron, E. D. (2011). Successful cutaneous delivery of the photosensitizer silicon phthalocyanine Pc 4 for photodynamic therapy. Clin. Exp. Dermatol. doi: 10.1111/j.13652230.2010.03989.x. [Epub ahead of print].

Mang, T. S., Allison, R., Hewson, G., Snider, W., and Moskowitz, R. (1998). A phase II/III clinical study of tin ethyl etiopurpurin (Purlytin)induced photodynamic therapy for the treatment of recurrent cutane- ous metastatic breast cancer. Cancer J. 6, 378-384.

Miller, J. D., Baron, E. D., Scull, H., Hsia, A., Berlin, J. C., McCormick, T., Colussi, V., Kenney, M. E., Cooper, K. D., and Oleinick, N. L. (2007). Photodynamic therapy with the phthalocyanine photosensitizer Pc 4: the case experience with preclinical mechanistic and early clinicaltranslational studies. Toxicol. Appl. Pharmacol. 224, 290-299.

Morton, C. A., McKenna, K. E., and Rhodes, L. E. (2008). Guidelines for topical photodynamic therapy: update. Br. J. Dermatol. 159, 1245-1266.

Ohtola, J., Sugiyama, H., Rodriguez, M.E., Oleinick, N. L., Lam, M., McCormick, T. S., Cooper, K. D., and Baron, E. D. (2010). Photodynamic therapy with the phthalocyanine Pc 4 for $\mathrm{T}$ cell mediated diseases: activated $\mathrm{T}$ cells exhibit increased uptake of Pc 4 and increased susceptibility to PDT-mediated cell death. J. Invest. Dermatol. 130, S129.

Oleinick, N. L., Antunez, A. R., Clay, M. E., Rihter, B. D., and Kenney, M. E. (1993). New phthalocyanine photosensitizers for photodynamic therapy. Photochem. Photobiol. 57, 242-247.

Oleinick, N. L., Morris, R. L., and Belichenko, I. (2002). Apoptosis in response to photodynamic therapy: what, where, why, and how. Photochem. Photobiol. Sci. 1, 1-21.

Oseroff, A. R., Blumenson, L. R., Wilson, B. D., Mang, T.S., Bellnier, D. A., Parsons, J. C., Frawley, N., Cooper, M.,Zeitouni, N., and Dougherty, T. J. (2006). A dose ranging study of photodynamic therapy with porfimer sodium (Photofrin) for treatment of basal cell carcinoma. Lasers Surg. Med. 38, 417-426.

Renschler, M. F., Yuen, A. R., Panella, T. J., Wieman, T. O., Dougherty, S., Esserman, L., Panjehpour, M., Taber, S. W., Fingar, V. M., Lowe, E., Engel, J. S., Lum, B., and Woodburn, K. (1998). Photodynamic therapy trials with lutetium texaphyrin (Lu-Tex) in patients with locally recurrent breast cancer. Proc. SPIE 3247, 35-39.

Triesscheijn, M., Baas, P. Schellens, J. H. M., and Stewart, F. A. (2006). Photodynamic therapy in oncology. Oncologist 11, 1034-1044.

Wyss, P., Schwarz, V., DoblerGirdziunaite, D., Hornung, R., Walt, H., Degen, A., and Fehr, M. K. (2001). Photodynamic therapy of locoregional breast cancer recurrences using a chlorin-type photosensitizer. Int. J. Cancer 93, 720-724.

Zaidi, S. I. A., Oleinick, N. L., Zaim, M. T., and Mukhtar, H. (1993). Apoptosis during photodynamic therapyinduced ablation of RIF-1 tumors in $\mathrm{C} 3 \mathrm{H}$ mice: electron microscopic, histopathologic, and biochemical evidence. Photochem. Photobiol. 58, 771-776.

Conflict of Interest Statement: Four of the authors (E. D. Baron, K. D. Cooper, M. E. Kenney, N. L. Oleinick) are associated with Fluence Therapeutics, Inc., a start-up company that is developing Pc 4-PDT for the treatment of psoriasis.

Received:08 May 2011;paperpending published:01 June 2011; accepted: 19June 2011; published online: 30 June 2011.

Citation: Kinsella TJ, Baron ED, Colussi VC, Cooper KD, Hoppel CL, Ingalls ST, Kenney ME, Li X, Oleinick NL, Stevens SR and Remick SC (2011) Preliminary clinical and pharmacologic investigation of photodynamic therapy with the silicon phthalocyanine photosensitizer Pc 4 for primary or metastatic cutaneous cancers. Front. Oncol. 1:14. doi: 10.3389/fonc.2011.00014

This article was submitted to Frontiers in Radiation Oncology, a specialty of Frontiers in Oncology.

Copyright ( $(2011$ Kinsella, Baron, Colussi, Cooper, Hoppel, Ingalls, Kenney, Li, Oleinick, Stevens and Remick. This is an open-access article subject to a non-exclusive license between the authors and Frontiers Media $S A$, which permits use, distribution and reproduction in other forums, provided the original authors and source are credited and other Frontiers conditions are complied with. 